islet preparations $(4,5,17,18)$. Our inability to detect $\beta$ receptors on B cells and $\alpha$ receptors on A cells is, however, at variance with earlier studies in humans (2) and in isolated pancreatic tissue $(5,18)$. The absence of a second type of adrenergic recognition in purified A or B cells cannot be attributed to receptor damage for the following reasons: (i) all studies were carried out on cultured cells, which should have recovered from membrane damage; (ii) both $\alpha$ and $\beta$ receptors were found to remain present on the purified cells, be it on different populations; (iii) the identified receptors were sensitive to catecholamine concentrations that were 10 to 100 times lower than those used in previous studies (3-5, 17); (iv) the purification process was previously shown to maintain high-affinity receptors on the membrane of purified cells (19). It seems likely, therefore, that the apparent discrepancy with previous reports is either related to species differences (2) or caused by misinterpretations in unpurified islet cell models.
Our results clarify the mechanisms involved in the adrenergic control of insulin and glucagon release and document the primordial role of the adrenergic tone on the secretory responsiveness of pancreatic $A$ and B cells to nutrient stimuli. On the basis of these observations, a more specific approach can be undertaken to assess the participation of the adrenergic system in the pathogenesis and treatment of diabetes mellitus.

\section{REFERENCES AND NOTES}

1. P. E. Cryer, N. Engl. J. Med. 303, 436 (1980).

2. D. Porte, Jr., and R. H. Williams, Science 152, 1248 (1966); D. Porte, Jr., J. Clin. Invest. 46, 86 (1967) J. E. Gerich et al., ibid. 53, 1441 (1974).

3. H. G. Coore and P. J. Randle, Biochem. J. 93, 66 (1964); V. Leclercg-Meyer, G. R. Brisson, W. J. Malaisse, Nature (London) (New Biol.) 231, 248 (19.71); R. L. Sorenson, R. P. Elde, V. Seybold Diabetes 28, 899 (1979).

4. J. R. Turtle and D. M. Kipnis, Biochem. Biophys. Res. Commun. 28, 797 (1967)

5. A. Rabinovitch, E. Cerasi, G. W. G. Sharp, Endocrinology 102, 1733 (1978); S. Ullich and C. B Wollheim, J. Biol. Chem. 259, 4111 (1984).

6. D. Pipeleers, P. in't Veld, E. Maes, M. Van De Winkel, Proc. Natl. Acad. Sci. U.S.A. 79, 7322 (1982).
7. D. G. Pipeleers et al., Endocrinology 117, 824 (1985).

8. D. G. Pipeleers, F. C. Schuit, C. F. H. Van Schravendijk, M. Van De Winkel, ibid., p. 817; D. G. Pipeleers, Horm. Res., in press.

9. D. G. Johnson, D. P. Henry, J. Moss, R. H. Williams, Diabetes 25, 198 (1976).

10. M. Van De Winkel, E. Maes, D. Pipeleers, Biochem. Bioplyys. Res. Commun. 107, 525 (1982).

11. D. G. Pipeleers et al., Endocrinology 117, 806 (1985).

12. F. C. Schuit and D. G. Pipeleers, ibid., p. 834

13. J. M. P. Holly and H. L. J. Makin, Anal. Biochem. 128, 257 (1983)

14. G. Burnstock and J. H. Szurszewski, Neurosci. Res. Progr. Bull. 17, 379 (1979).

15. P. Rooth and I.-B. Täljedal, Diabetes Res. Clin. Pract. 1, S477 (1985) (Abstr.).

16. R. H. Unger and L. Orci, N. Engl. J. Med. 304, 1518 (1981); J. B. Halter, J. C. Beard, D. Porte, Jr., Am. J. Physiol. 247, E47 (1984).

17. T. Nakaki, T. Nakadate, $K$. Ishii, $R$. Kato, $J$. Pharmacol. Exp. Ther. 216, 607 (1981).

18. J. Iversen, J. Clin. Invest. 52, 2102 (1973); E. Samols and G. C. Weir, ibid. 63, 230 (1979).

19. C. F. H. Van Schravendijk et al., Endocrinology 117, 841 (1985).

20. We thank M. Jacobs and J. C. Hannaert for technical assistance, P. Smets and L. Kaufman for statistical advice, and A. Dehoux for secretarial help. Supported by grants from the Belgian Ministerie Wetenschapsbeleid (80/85-9) and by the Fonds Geneeskundig Wetenschappelijk Onderzoek (3.00.66.84). F.S was research assistant at the National Fund for Scientific Research (Belgium).

4 November 1985; accepted 6 March 1986

\title{
Trans-Activator Gene of HTLV-II Induces IL-2 Receptor and IL-2 Cellular Gene Expression
}

\author{
Warner C. Greene, Warren J. Leonard, Yuji Wano, \\ Penny B. Svetlik, Nancy J. Peffer, Joseph G. Sodroski, \\ Craig A. Rosen, Wei Chun Goh, William A. Haseltine
}

The human T-lymphotropic viruses types I and II (HTLV-I and -II) have been etiologically linked with certain $T$-cell leukemias and lymphomas that characteristically display membrane receptors for interleukin-2. The relation of these viruses to this growth factor receptor has remained unexplained. It is demonstrated here that introduction of the trans-activator (tat) gene of HTLV-II into the Jurkat T-lymphoid cell line results in the induction of both interleukin-2 receptor and interleukin-2 gene expression. The coexpression of these cellular genes may play a role in the altering $T$ cell growth following retroviral infection.

$\mathrm{T}$ The hUMAN T-LYMPhOTROPIC VIruses types I and II (HTLV-I and -II) are associated with certain T-cell leukemias and lymphomas (1). Both of these retroviruses can transform primary human $\mathrm{T}^{+} \mathrm{T}$ cells in culture (2). Leukemic T-cell lines that are infected with HTLV-I or -II uniformly display large numbers of membrane receptors for interleukin-2 (IL-2) (3) and some, but not all, of these cell lines produce IL-2 (4). At present, the mechanism of transformation by these retroviruses remains unknown. However, neither HTLV-I nor HTLV-II contains a recognized oncogene nor do these viruses appear to activate cellular oncogenes by $c$ is insertion of retroviral promoter (or enhancer) sequences, since the sites of proviral integra- tion vary from tumor to tumor (5). An unusual feature of the HTLV-I and -II viruses is that they encode a gene whose protein product greatly stimulates the expression of other viral genes controlled by the long terminal repeat sequences (LTR's) (6). The elements of this autostimulatory control mechanism are the trans-activator proteins tat-I $(42 \mathrm{kD})$ and tat-II $(38 \mathrm{kD})$, which are encoded by a long open reading frame within the $\mathrm{pX}$ region (7) at the $3^{\prime}$ end of the viral genomes, and the trans-acting responsive sequences TAR-I and TAR-II, which are located within the viral LTR's $(8)$. It has been suggested that the tat proteins may also be able to alter the expression of certain cellular genes involved in T-cell growth $(6,9)$. To test this possibility, we have introduced a functional tat-II gene into Jurkat $T$ and Raji $B$ cells and examined these cells for changes in the expression of cellular genes including IL-2 and the IL-2 receptor.

The tat-II gene from HTLV-II was isolated as a Bgl II-Bam HI fragment from pCATLORIIgpt (6) and inserted into the Bam HI site of the PZIPNEOSV $(X)$ retroviral vector described by Cepko et al. (10). This plasmid has been described elsewhere (11). Plasmids containing the neo gene and tat-II in both the sense (pZIP-tat-II) and anti-sense (pZIP-anti-tat-II) orientation were identified and transfected into psi AM fibroblast cells $(12)$ by calcium phosphate precipitation (13). Psi AM cells containing these plasmids were isolated by culture in medium containing the G418 antibiotic $(400 \mu \mathrm{g} / \mathrm{ml})$. The resultant amphotropic viruses produced by the neo-resistant psi AM cells were used to infect Jurkat $\mathrm{T}$ cells and Raji B cells (11). Infected Jurkat T- and Raji B-cell colonies were isolated by plating 10,000 cells per microliter well and culturing in G418 antibiotic $(700 \mu \mathrm{g} / \mathrm{ml})$.

Jurkat $\mathrm{T}$ and Raji $\mathrm{B}$ cells containing tat-II were first analyzed for the production of functional tat-II protein. Although derived

W. C. Greene, Y. Wano, P. B. Svetlik, N. J. Peffer, Metabolism Branch, National Cancer Institute, Bethesda, MD 20892.

W. J. Leonard, Cell Biology and Metabolism Branch National Institute of Child Health and Human Development, Bethesda, MD 20892.

J. G. Sodroski, C. A. Rosen, W. C. Goh, W. A. Haseltine, Dana-Farber Cancer Institute, Boston, MA 02115. 
Table 1. The tat-II protein activates expression of IL-2 receptors in Jurkat T cells. Each cell line was examined for IL-2 receptor expression by means of a binding assay with ${ }^{3} \mathrm{H}$-labeled anti-Tac (19). Similar results were obtained in six additional experiments.

\begin{tabular}{lr}
\hline \multicolumn{1}{c}{ Cells lines } & $\begin{array}{r}\text { Receptors } \\
\text { (No./cell) }\end{array}$ \\
\hline HTLV-I infected HUT 102B2 & 92,380 \\
Nontransfected Jurkat & $<50$ \\
Jurkat-tat-II-6 & 1,360 \\
Jurkat-tat-II-7 & 1,170 \\
Jurkat-tat-II-21-1 & 510 \\
Jurkat-tat-II-21-8 & 420 \\
Jurkat-anti-tat-II-16-1 & $<50$ \\
Jurkat-anti-tat-II-16-3 & $<50$ \\
Jurkat-anti-tat-II-16-4 & $<50$ \\
Raji-tat-II-2l-2 & $<50$ \\
Raji-anti-tat-II-16-1 & $<50$ \\
\hline
\end{tabular}

from HTLV-II, the tat-II protein, like tat-I, efficiently activates the transcription of genes controlled by the LTR of HTLV-I (6). As an indicator gene, the bacterial chloramphenicol acetyl transferase (CAT) gene was placed 3' to the HTLV-I LTR (pU3R1 plasmid) and $3^{\prime}$ to the $S V 40$ early region promoter (pSV2CAT). These plasmids were then transfected with DEAE dextran into Jurkat $T$ and Raji B cells containing the tat-II gene in the sense or anti-sense orientation. Promoter activity was measured by determining the magnitude of conversion of ${ }^{14} \mathrm{C}$-labeled chloramphenicol substrate into acetylated forms separated by thin-layer chromatography (14). As shown in Fig. 1, both Jurkat T cells and Raji B cells containing the sense tat-II gene expressed greatly elevated levels of CAT when transfected with the pU3R-1 plasmid compared with the anti-sense tat-II cell lines. In contrast, pSV2CAT expression was not enhanced in Jurkat or Raji cells containing the sense tatII gene. In additional studies with serum from a patient with HTLV-I-induced leukemia, the tat-II protein with a relative molecular mass $\left(M_{r}\right)$ of 38,000 was immunoprecipitated from $\left[{ }^{35} \mathrm{~S}\right]$ methionine-labeled Jurkat and Raji cell extracts containing the sense, but not anti-sense, tat-II gene. We concluded that both the Jurkat $T$ and Raji B cells infected with the sense tat-II gene express functional tat-II trans-activator protein.

The Jurkat and Raji cells containing tat-II were next analyzed for possible changes in the expression of the IL-2 receptor gene. Northern blots prepared with polyadenylated RNA from each cell line and HTLV-I-infected HUT 102B2 cells were probed with radiolabeled IL-2 receptor complementary DNA (cDNA) (15). IL-2 receptor messenger RNA (mRNA) was detected in Jurkat $\mathrm{T}$ cells containing the sense tat-II gene (Jurkat-tat-II-6 and -7), but not in nontransfected parental Jurkat $T$ cells nor in Jurkat $\mathrm{T}$ cells containing the anti-sense tat-II gene (Jurkat-anti-tat-II-16-1, -16-3, -16-4) (Fig. 2, A and B). Unlike Jurkat T cells, the presence of tat-II in Raji cells did not activate IL-2 receptor mRNA expression (Fig. 2B). Two different size classes of IL-2 receptor $m R N A$, generated by the use of different $3^{\prime}$ polyadenylation signal sequences $(15,16)$, were present in these cells. However, these cells contained considerably greater quantities of the larger, 3500-base form of receptor mRNA. This finding is analogous to the pattern of receptor $\mathrm{mRNA}$ expression in Jurkat $\mathrm{T}$ cells stimulated with phytohemagglutinin (PHA) and phorbol 12-myristate 13-acetate (PMA) (Fig. 2A) or normal $\mathrm{T}$ cells exposed to suboptimal activation signals, but is in contrast to ATL cell lines, including HUT 102 (Fig. 2, A and B) which contain nearly equivalent amounts of both forms of receptor mRNA (17).

The induction of IL-2 receptor $m R N A$ expression in the Jurkat-tat-II cells was not the result of a generalized increase in the transcription of all cellular genes. Hybridization of the same blots with c-myc, transferrin receptor, actin, and class I major histocompatibility antigen DNA probes revealed nearly equivalent amounts of these mRNA's in the sense and anti-sense tat-II cells.

We next evaluated whether Jurkat-tat-II-6 and -7 cells displayed surface IL-2 receptors. As shown in Fig. 3, indirect immunofluorescent staining with anti-Tac (a monoclonal antibody to the IL-2 receptor) (18) revealed the presence of receptors on the Jurkat-tatII-6 cells but not on parental Jurkat cells or cells containing the anti-sense tat-II gene. Comparison of the mean fluorescence intensity of Jurkat-tat-II cells with HUT 102B2 cells suggested that the tat-II transfectants contained fewer receptors than the HTLVI-infected HUT 102B2 cells.

To determine more precisely the number of IL-2 receptors expressed, we performed binding assays with ${ }^{3} \mathrm{H}$-labeled anti-Tac (19). As shown in Table 1, Jurkat-tat-II-6 and -7 cells, respectively, expressed 1360 and 1170 anti-Tac binding sites per cell

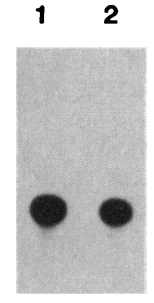

6060

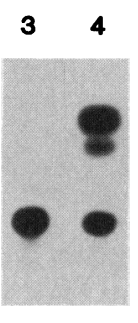

$60 \quad 15$

pU3R-I

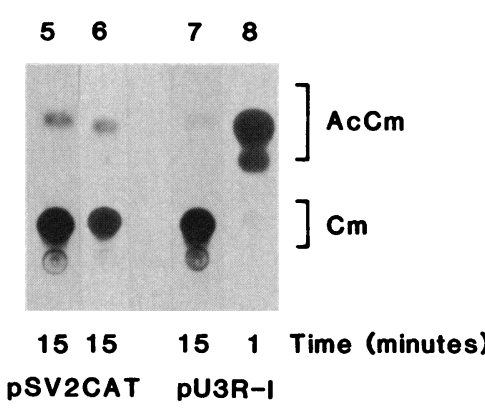

Fig. 1. Levels of HTLV-I LTR directed CAT expression in cell lines containing the tat-II gene. The cell lines indicated were transfected $(30)$ with $2 \mu \mathrm{g}$ of either pSV2CAT (14) or pU3R-1 (6). Plasmid pSV2CAT contains the SV40 early region promoter sequences $5^{\prime}$ to the CAT gene whereas pU3R-1 contains nucleotides -350 to +315 of the HTLV-I LTR $5^{\prime}$ to CAT. CAT assays were performed 48 hours after transfection as previously described (14). Cell lysates were incubated with ${ }^{14} \mathrm{C}$-labeled chloramphenicol and acetyl $\mathrm{COA}$ for the times indicated. The nonacetylated chloramphenicol $(\mathrm{Cm})$ and acetylated reaction products $(\mathrm{AcCm})$ separated by thin-layer chromatography are indicated. Cell lines: 1 and 3, Jurkat-anti-tat-II-16-1; 2 and 4, Jurkat-tat-II-6; 5 and 7, Raji-anti-tat-II-16-1; 6 and 8, Raji-tat-II-212.

Table 2. Bioassay of IL-2 activity in supernatants from tat-II cell lines. IL-2 activity was detected after 3 days of culture by the CTLL bioassay described (23). Dilutions of supernatants and corresponding mean incorporation of $\left[{ }^{3} \mathrm{H}\right]$ thymidine (counts per minute) in triplicate cultures of CTLL cells (4000 per well) are shown. The proliferative response of these CTLL cells after the addition of various concentrations of purified recombinant IL-2 is also shown. Similar results were obtained in four additional experiments.

\begin{tabular}{|c|c|c|c|c|c|c|c|c|c|}
\hline $\begin{array}{l}\text { Supernatant } \\
\text { dilution }\end{array}$ & Jurkat & $\begin{array}{l}\text { Jurkat- } \\
\text { tat-II-6 }\end{array}$ & $\begin{array}{l}\text { Jurkat- } \\
\text { tat-II-7 }\end{array}$ & $\begin{array}{l}\text { Jurkat-anti- } \\
\text { tat-II-16-1 }\end{array}$ & $\begin{array}{l}\text { Jurkat-anti- } \\
\text { tat-II-16-3 }\end{array}$ & $\underset{\text { tat-II-2l-2 }}{\text { Raji- }}$ & $\begin{array}{l}\text { Raji-anti- } \\
\text { tat-II-16-1 }\end{array}$ & $\begin{array}{l}\text { Recombinant } \\
\text { IL-2 }\end{array}$ & Control \\
\hline $\begin{array}{l}2^{2} \\
2^{3} \\
2^{4} \\
2^{5} \\
2^{6}\end{array}$ & $\begin{array}{l}672 \\
803 \\
706 \\
587 \\
653\end{array}$ & $\begin{array}{r}7,220 \\
3,492 \\
2,043 \\
1,293 \\
842\end{array}$ & $\begin{array}{l}9,454 \\
6,147 \\
3,563 \\
3,652 \\
1,229\end{array}$ & $\begin{array}{l}800 \\
796 \\
756 \\
686 \\
757\end{array}$ & $\begin{array}{r}822 \\
1,060 \\
775 \\
840 \\
800\end{array}$ & $\begin{array}{r}1,533 \\
1,033 \\
1,217 \\
990 \\
1,021\end{array}$ & $\begin{array}{l}1,998 \\
2,058 \\
1,522 \\
1,245 \\
1,272\end{array}$ & $\begin{array}{l}(100 \mathrm{ng} / \mathrm{ml}) \\
(10 \mathrm{ng} / \mathrm{ml}) \\
(1 \mathrm{ng} / \mathrm{ml}) \\
(0.1 \mathrm{ng} / \mathrm{ml}) \\
(0.01 \mathrm{ng} / \mathrm{ml}) \\
\text { Medium only }\end{array}$ & $\begin{array}{r}11,062 \\
10,371 \\
11,536 \\
7,912 \\
4,068 \\
572\end{array}$ \\
\hline
\end{tabular}


while HUT 102B2 cells displayed more than 92,000 sites per cell. Two other independently isolated Jurkat-tat-II lines (21-1 and 21-8), contained 400 to 500 anti-Tac binding sites per cell. In agreement with the Northern blotting studies and flow microfluorometric assays, Jurkat-anti-tat-II cells, parental Jurkat cells, and Raji-tat-II cells did not contain significant numbers of IL-2 receptors (Table 1). Attempts to measure high-affinity IL-2 receptors were unsuccessful, possibly because of the low number of total IL-2 receptors displayed. In most cell lines, the high-affinity IL-2 receptor class constitutes only 5 to 10 percent of the total IL-2 binding sites (20).

Radiolabeled membrane proteins were solubilized in detergent and immunoprecipitated with anti-Tac. This revealed that the IL-2 receptors on the surface of the Jurkat-tat-II- 6 and -7 cells migrated with an apparent $M_{r}$ of 55,000, which was similar to the size of receptors expressed on PHAactivated normal $\mathrm{T}$ cells $(21)$ or Jurkat $\mathrm{T}$ cells induced with PHA and PMA. In contrast, proteins reactive with anti-Tac were not detected in nontransfected Jurkat $T$ cells or cells containing the anti-sense tat-II gene.

We next investigated expression of the IL2 gene in Jurkat cells containing tat-II. As shown in Fig. 4, hybridization of radiolabeled IL-2 cDNA (22) to Northern blots prepared with the same RNA's as used in Fig. 2 identified the presence of IL-2 mRNA in Jurkat-tat-II- 6 and -7 cells and Jurkat cells stimulated with PHA and PMA. The parental Jurkat cells, the cells infected with the anti-sense tat-II, and the Raji-tat-II cells contained no detectable IL-2 mRNA.

Supernatants from these various cell lines were also analyzed for the presence of secreted IL-2 protein by means of a sensitive bioassay (23). Jurkat-tat-II-6 and Jurkat-tatII-7 supernatants each contained IL-2 activity as evidenced by dose-related increases in $\left[{ }^{3} \mathrm{H}\right]$ thymidine incorporation in cells from a murine IL-2 dependent cytotoxic $\mathrm{T}$ lymphocytic cell line (CTLL) (Table 2). In contrast, anti-sense constructs of tat-II did not activate the synthesis and secretion of IL-2 into the medium. Similarly, Raji-tat-II cells did not produce detectable IL-2 activity.

In summary, these data demonstrate that the tat-II gene can induce the expression of both the IL-2 receptor and IL-2 genes in Jurkat $T$ cells. Induction of these genes appears to be a consequence of the expression of the tat-II gene product because Jurkat cells that contain the gene in a configuration unsuitable for its expression produce neither IL-2 nor IL-2 receptors. The induced expression of IL-2 receptor and IL-2 mRNA by the tat-II protein reflects a specif-
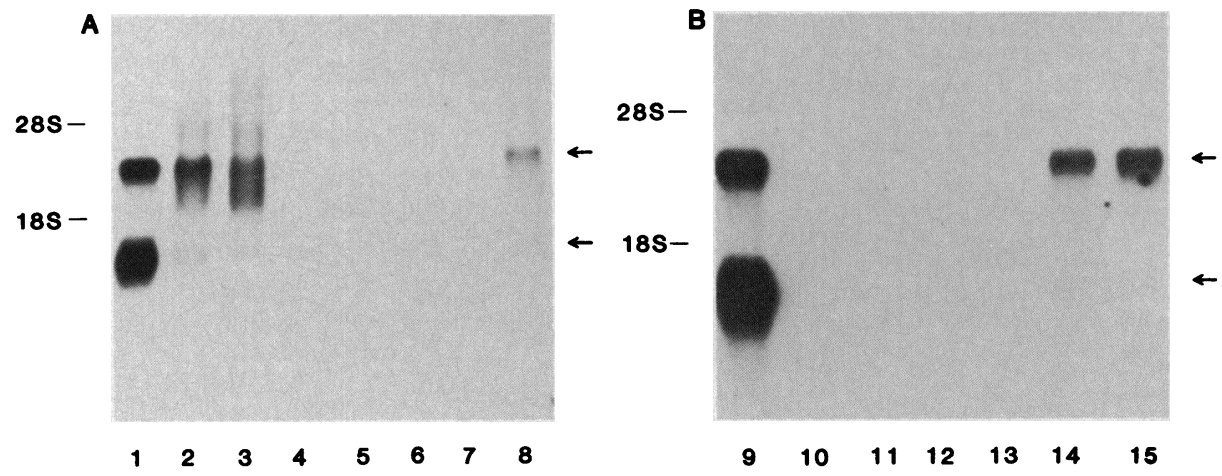

Fig. 2. Northern blotting analysis of tat-II induced IL-2 receptor mRNA expression. RNA was prepared from each cell line by the method of Chirgwin (31) and the poly $(\mathrm{A})^{+}$fraction was enriched by oligo(dT) cellulose affinity chromatography (32). Ten micrograms of each RNA sample was size fractionated by formaldehyde-agarose gel electrophoresis and transferred to nitrocellulose filters (33). The filters were subsequently hybridized with ${ }^{32} \mathrm{P}$-labeled IL-2 receptor CDNA radiolabeled by the random priming method of Feinberg and Vogelstein (34). Conditions of filter hybridization and washing were as previously described (15). Similar results were obtained with four independent preparations of RNA. Cell lines: 1 and 9, HUT 102B2; 2 and 15, Jurkat-tat-II-7; 3 and 14, Jurkat-tatII-6; 4, Jurkat-anti-tat-II-16-4; 5, Jurkat-anti-tat-II-16-3; 6, Jurkat-anti-tat-II-16-1; 7 and 13, nontransfected Jurkat; 8, Jurkat induced with PHA and PMA; 10, Raji-anti-tat-II-16-1; 11, Raji-tat-II-212; 12, Raji-tat-II-21-3.

ic rather than generalized increase in the gene transcription since the Jurkat-tat-IIand anti-tat-II-infected cells express similar levels of c-myc, transferrin receptor, actin, and class I major histocompatibility antigen mRNA's. Since the tat-I gene of HTLV-I is similar in structure and function to its counterpart in HTLV-II (6), one may predict from these findings that the tat-I gene can also induce IL-2 and IL-2 receptor expression.

The mechanism by which the tat-II protein activates the expression of the IL-2 and IL-2 receptor genes is unclear. In view of the
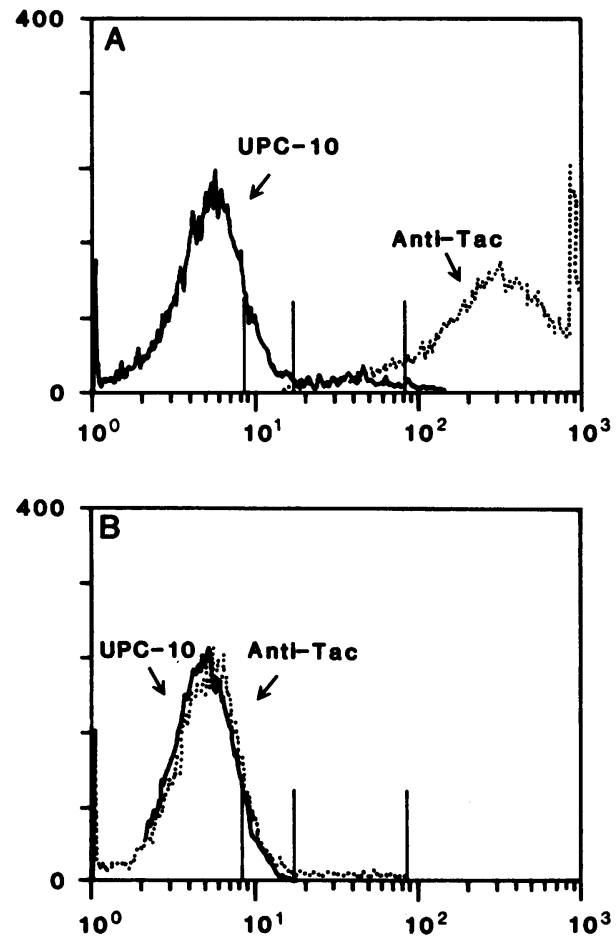

strong association of HTLV-I and -II with $\mathrm{T}^{+}{ }^{+} \mathrm{T}$-cell leukemias and lymphomas, the inability of the tat-II gene to induce IL-2 and IL-2 receptor gene expression in Raji B cells is notable. Infection of other non-T4 ${ }^{+}$ cells with HTLV-I or -II does not, in general, induce expression of the IL-2 receptor or IL-2. For example, no IL-2 receptors were detected in osteogenic sarcoma cells infected with HTLV-I (24) or, in our studies, feline epithelial cells infected with HTLV-II. Similarly, introduction of the tat-II gene into mouse fibroblasts or feline epithelial cells does not induce IL-2 receptor or IL-2 gene

Fig. 3. Anti-Tac and UPC-10 indirect immunofluorescent staining and fluorescent-activated cell sorting analysis of (A) HTLV-I-infected HUT 102B2 cells, (B) nontransfected parental Jurkat $\mathrm{T}$ cells, and (C) Jurkat-tat-II-6 cells. The cell lines were processed for indirect immunofluorescence with the use of anti-Tac and UPC-10 monoclonal antibodies in the first step and fluorescein isothiocyanate (FITC)-conjugated goat antiserum to mouse immunoglobulin $\mathbf{G}$ in the second step as described (19). Cells were then analyzed on a Becton Dickinson FACS Analyzer with cell number displayed on the ordinate and fluorescence on the abscissa.

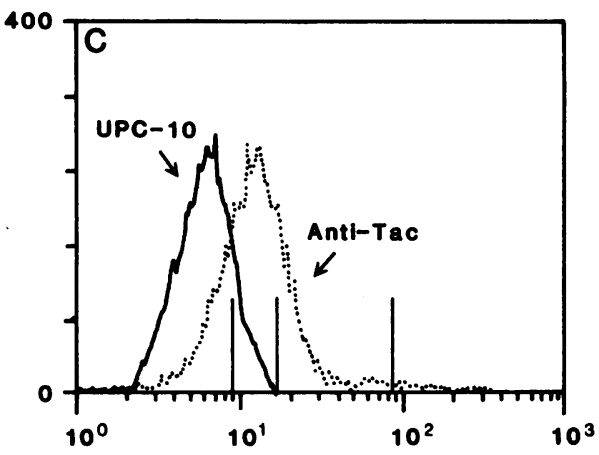




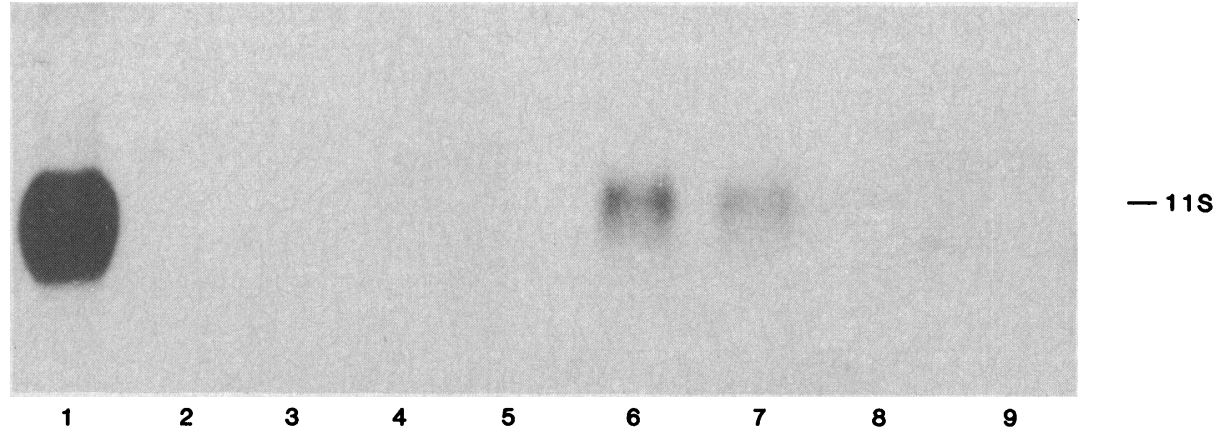

Fig. 4. Northern blotting analysis of tat-II-induced IL-2 mRNA expression. RNA samples described in Fig. 2 were analyzed for the presence of IL-2 mRNA with ${ }^{32}$ P-labeled IL-2 cDNA (22). Induced Jurkat T-cell RNA was isolated after 12 hours of stimulation of these cells with PHA (1 $\mu \mathrm{g} / \mathrm{ml})$ and PMA (50 $\mathrm{ng} / \mathrm{ml}$ ). Cell lines: 1, PHA- and PMA-induced Jurkat; 2, uninduced Jurkat; 3, Jurkat-anti-tat-II-16-1; 4, Jurkat-anti-tat-II-16-3; 5, Jurkat-anti-tat-II-16-4; 6, Jurkat-tat-II-6; 7, Jurkat-tat-II-7; 8, Raji-antitat-II-16-1; 9, Raji-tat-II-21-2.

expression. Thus, induction of the IL-2 receptor and IL-2 genes may reflect a specific response of certain cell lineages to the trans-activator gene of HTLV-I and -II. It is possible that only $\mathrm{T}$ cells, or perhaps only the $\mathrm{T}^{+}$subset of $\mathrm{T}$ cells, are susceptible to the effects of the trans-activator protein. However, against this argument is the finding that B-cell lines can be infected with HTLV-I in vitro (25) and that some of these cells display IL-2 receptors.

The Jurkat-tat-II cell lines, while expressing IL-2 receptor $\mathrm{mRNA}$ and protein, do so at a much lower level than $T$ cells containing integrated complete HTLV-I or HTLV-II proviruses. This finding could reflect an intrinsic property of the Jurkat cell line used in these studies. Alternatively, the low levels of tat-II protein produced in the Jurkat-tatII cells may be responsible for the low level of IL-2 receptor expression. Unlike HTLVI and -II, the tat protein does not transactivate its own production in pZIP-tat-II since the appropriate trans-acting responsive sequences (TAR) are not present in the Moloney virus LTR of this plasmid.

The induced coexpression of IL-2 and its cellular receptor by the tat-II protein raises the possibility that infection with HTLV-I or HTLV-II results in an autocrine mechanism of cell growth. A model involving autocrine stimulation in HTLV-I-induced adult T-cell leukemia (ATL) was previously considered (26), but later dismissed when it was demonstrated that the majority of longterm cultured ATL cell lines neither secreted IL-2 nor contained IL-2 mRNA (4). However, those findings with long-term cultured ATL cells or freshly isolated tumor cells from patients with well-established disease do not exclude a role for IL-2/IL-2 receptor-mediated autocrine growth during the early phases of retroviral-mediated T-cell transformation. Precedence for such a model involving early growth factor dependence followed by progression to growth factor independence may be found in other tumor systems including primary plasmacytomas (27), Friend virus-induced myeloid leukemia (28), and Burkitt's lymphoma associated with Epstein-Barr virus infection (29). It is possible that the development of HTLVI-and -II-induced leukemia may follow a similar progression from early growth factor dependence to later independence and that soon after viral infection, the coordinate production IL-2 and display of IL-2 receptors mediates autocrine polyclonal growth of these retrovirus-infected T cells. The subsequent intracellular events that culminate in the emergence of clonal, growth factorindependent leukemic $\mathrm{T}$-cell populations are undefined, but appear to be associated with persistent high-level IL-2 receptor display accompanied by a loss of IL-2 gene expression. Thus, it seems likely that the tat gene is required, but alone is insufficient, to produce complete leukemic transformation of normal $\mathrm{T}$ cells.

\section{REFERENCES AND NOTES}

1. B. J. Poiesz et al., Proc. Natl. Acad. Sci. U.S.A. 77, 7415 (1980); B. J. Poiesz, F. W. Ruscetti, M. D. Reitz, V. S. Kalyanaraman, R. C. Gallo, Nature (London) 294, 268 (1981); Y. Hinuma et al., Proc. Natl. Acad. Sci. U.S.A. 78, 6476 (1981); M. Yoshida, I. Miyoshi, Y. Hinuma, ibid. 79, 2131 (1982); V. S. Kalyanaraman et al., Science 218, 571 (1982).

2. I. Miyoshi et al., Nature (London) 294, 770 (1981); M. Popovic, G. Lange-Watzin, P. S. Sarin, D. Mann, R. C. Gallo, Proc. Natl. Acad. Sci. U.S.A. 80, 5402 (1983); I. S. Y. Chen, S. G. Quan, D. N. Golde, ibid., p. 4006

3. J. E. Gootenberg, F. W. Ruscetti, J. W. Mier; A. Gazdar, R. C. Gallo, J. Exp. Med. 154, 1403 (1981); T. Hattori, T. Uchiyama, T. Toibana, K. Takatsuki, H. Uchino, Blood 58, 645 (1981); T. A. Waldmann et al.,J. Clin. Invest. 73, 1171 (1984); J. M. Depper, W. J. Leonard, M. Krönke, T. A. Waldmann, W. C. Greene, J. Immunol. 122, 1691 (1984).

4. S. K. Arya, F. Wong-Staal, R. C. Gallo, Science 223, 1086 (1984)

5. M. Seiki, R. Eddy, T. B. Eddy, T. B. Shows, M. Yoshida, Nature (London) 309, 640 (1984).

6. J. G. Sodroski, C. A. Rosen, W. A. Haseltine, Science 225, 381 (1984); J. Sodroski, C. Rosen, W. C.
Goh, W. Haseltine, ibid. 228, 1430 (1985); J. G. Sodroski, R. Patarca, C. A. Rosen, F. Wong-Staal, W. A. Haseltine, ibid. 229, 74 (1985); I. S. Y. Chen et al., ibid., p. 54; M. Seiki, A. Hikikoshi, T. Taniguchi, M. Yoshida, ibid. 228, 1532 (1985); W. Wachsman et al., ibid., p. 1534; A. M. Fisher, E. Collati, L. Ratner, R. C. Gallo, F. Wong-Staal, Nature (London) 316, 262 (1985); B. K. Felber, H. Paskalis, C. Kleinman-Ewing, F. Wong-Staal, G. N. Pavlakis, Science 229, 675 (1985)

7. M. Seiki, S. Hattori, Y. Hirayama, M. Yoshida, Proc. Natl. Acad. Sci. U.S.A. 80, 3618 (1983).

8. C. A. Rosen, J. G. Sodroski, W. A. Haseltine, ibid. 82, 6502 (1985).

9. F. Wong-Staal and R. C. Gallo, Nature (London) 317,395 (1985)

10. C. L. Cepko, B. E. Roberts, R. C. Mulligan, Cell 37, 1053 (1984)

11. C. A. Rosen, J. G. Sodroski, K. Campbell, W. A. Haseltine, J. Virol. 57, 379 (1986).

12. R. D. Cone and R. C. Mulligan, Proc. Natl. Acad. Sci. U.S.A. 81, 6349 (1984).

13. M. Wigler et al., Cell 16, 777 (1979).

14. C. M. Gorman, G. T. Merlino, M. C. Willingham, I. Pastan, B. Howard, Proc. Natl. Acad. Sci. U.S.A. 79, 6777 (1982)

15. W. J. Leonard et al., Nature (London) 311, 626 (1984)

16. W. J. Leonard, M. Krönke, N. J. Peffer, J. M. Depper, W. C. Greene, Proc. Natl. Acad. Sci. U.S.A. 82, 6281 (1985); W. J. Leonard, J. M. Depper, M. Kanehisa, M. Krönke, N. J. Peffer, P. B. Svetlik, M. Sullivan, W. C. Greene, Science 230, 633 (1985).

17. M. Krönke, W. J. Leonard, J. M. Depper, W. C. Greene, Science 228, 1215 (1985)

18. T. Uchiyama, S. Broder, T. A. Waldmann, J. Immunol. 126, 1293 (1981); W. J. Leonard et al., Nature (London) 300, 267 (1982); R. J. Robb and W. C. Greene, J. Exp. Med. 158, 1332 (1983).

19. J. M. Depper et al., J. Immunol. 133, 3054 (1984)

20. R. J. Robb, W. C. Greene, C. M. Rusk, J. Exp. Med. 160, 1126 (1984)

21. W. J. Leonard, J. M. Depper, R. J. Robb, T. A. Waldmann, W. C. Greene, Proc. Natl. Acad. Sci. U.S.A. 80, 6957 (1983); Y. Wano et al., J. Immunol. 132, 3005 (1984); W. J. Leonard et al., J. Biol. Chem. 260, 1872 (1985)

22. The IL-2 cDNA was a gift of N. Holbrook and G. R. Crabtree.

23. S. Gillis, M. Ferm, W. Ou, K. A. Smith, J. Immunol. 120, 2027 (1978).

24. P. Clapham, K. Nagy, R. Cheingsong-Popov, M. Exley, R. A. Weiss, Science 222, 1125 (1983).

25. N. Yamamoto, T. Matsumoto, T. Koyanagi, Y. Tanaka, Y. Hinuma, Nature (London) 249, 367 (1982); D. L. Mann et al., J. Clin. Invest. 74, 56 (1984); D. L. Longo et al., Nature (London) 310 , 505 (1984); S. Tomita et al., J. Exp. Med. 162, 393 $505(1984)$

26. R. C. Gallo and F. Wong-Staal, Blood 60, 545 (1982).

27. M. Cancro and M. Potter, J. Exp. Med. 144, 1554 (1976); M. Potter, J. S. Wax, A. O. Anderson, R. P. Nordan, ibid. 161, 996 (1985)

28. J. M. Heard et al., Mol. Cell. Biol. 4, 216 (1984).

29. B. A. Blazar, L. M. Sutton, M. Strome, Cancer Res. 43, 4562 (1983); J. Gordon, S. C. Ley, M. D. Melamed, P. Aman, N. C. Hughes-Jones, J. Exp. Med. 159, 1544 (1984); J. Gordon, S. C. Ley, M D. Melamed, L. S. English, N. C. Hughes-Jones, Nature (London) 310, 145 (1984)

30. C. Oueen and D. Baltimore, Cell 33, 741 (1983).

31. J. M. Chirgwin, A. E. Przybyla, R. J. MacDonald, W. J. Rutter, Biochemistry 18, 5294 (1979).

32. H. Aviv and P. Leder, Proc. Natl. Acad. Sci. U.S.A. 69, 1048 (1972)

33. H. D. Lehrach, D. Diamond, J. M. Wozney, $H$. Boedtker, Biochemistry 16, 4743 (1977).

34. A. P. Feinberg and B. Vogelstein, Anal. Biochem 132, 6 (1983).

35. We thank R. C. Gallo and F. Wong-Staal for providing the HTLV-II provirus, K. Campbell and R. Zaya for technical assistance, and Cetus Corporation for purified recombinant IL-2. Supported in part by NCI grant IR01CA369974-01AI to W.A.H.; Y.W. is sponsored by the Fogarty Visiting Fellowship Program; J.G.S. is a Special Fellow of the Leukemia Society of America and also supported by NIH grant CA40658; C.A.R. is supported by NIH grant CA07580.

18 November 1985; accepted 21 March 1986 